\title{
Subjective Well-Being and Self-Reported Health in Osteoarthritis Patients Before and After Arthroplasty
}

\author{
Anu Realo ${ }^{1,2} \cdot$ Janika Johannson $^{3} \cdot$ Monika Schmidt $^{2}$
}

Published online: 21 June 2016

(C) The Author(s) 2016. This article is published with open access at Springerlink.com

\begin{abstract}
The main aim of the current study is to examine the changes in the components of subjective well-being (SWB) over time in patients with osteoarthritis who have undergone total hip or knee replacement surgery (arthroplasty). We are also interested in determining whether pre-operative ratings of self-reported health (SRH) status, as well as change in health status, can serve as predictors for postoperative levels of SWB. To this end, 50 participants who had been admitted to a hospital for arthroplasty completed the measures twice-first at the clinic one day before the surgery, and then at home approximately 4.5 months after the surgery. Despite the fact that there were substantial improvements in participants' health and physical functioning after the arthroplasty, there were no changes in their ratings of general SRH, life satisfaction (LS), or negative affect (NA). The only change in SWB scores was in the level of positive affect (PA), which was significantly higher after surgery compared with the pre-operative measurement. LS, NA, and PA scores after arthroplasty were differentially predicted by health ratings, showing that, it is the cognitive-evaluative component of SWB (i.e., LS) that is mostly responsible for the association between general SRH and SWB while affective components (i.e., NA and PA) are primarily related to more specific health indicators. Our findings can assist physicians in their efforts to provide more realistic expectations for their patients undergoing surgery in terms of the physical and psychological outcome.
\end{abstract}

Keywords Subjective well-being - Life satisfaction - Positive affect · Negative affect · General self-reported health · Osteoarthritis · Arthroplasty

Anu Realo

anu.realo@ut.ee

Department of Psychology, University of Warwick, Coventry CV4 7AL, UK

2 Department of Psychology, University of Tartu, Tartu, Estonia

3 The Pärnu General Practitioners' Centre, Pärnu, Estonia 


\section{Introduction}

The last several decades have seen an upsurge in policy and research interest in subjective well-being (SWB), which has been defined as "a person's cognitive and affective evaluations of his or her life" (Diener et al. 2009, p. 63). In recent years, researchers' interest has moved away from studying the simple demographic correlates of SWB to examining and understanding the possible systemic causes and outcomes of SWB, including personality traits, life events, and health status. SWB is no longer seen as a mere outcome variable (e.g., "people are happy because they are rich"); on the contrary, there is now evidence showing that SWB can also predict and lead to future behavioral and other life outcomes (e.g., "people are rich because they are happy") (Luhmann et al. 2013; Lyubomirsky et al. 2005).

\subsection{SWB and Health}

One of the areas which has drawn the attention of many researchers concerns the relationship between SWB and health. Physical health is one of the important correlates of SWB, but only when self-reported health (SRH) ratings are used (George and Landerman 1984; Okun et al. 1984) - the correlation between SWB and health status is rather weak when more objective health ratings (such as hospitalization, doctor visits, confirmed diagnoses) are examined (Angner et al. 2009; Brief et al. 1993; Okun and George 1984; Watten et al. 1997). Concerning the causality of the relationship, several studies have shown that SWB causally contributes to health, with initial levels of SWB predicting important health outcomes in later life (Diener and Chan 2011). Yet, the causal role of SWB in health is far from being fully understood (Friedman and Kern 2014). Despite several prospective longitudinal studies that have shown that various types of SWB predict health and longevity, it is still possible that there is a third variable that influences both SWB and health and creates a 'false causal' association between them. Moreover, it cannot be excluded that it is in fact health that causally contributes to SWB, or that health and SWB are reciprocally related and influence each other during the life course. For instance, an 8-year longitudinal study of older adults by Gana et al. (2013) showed that life satisfaction did not influence health, but health showed a significant effect on life satisfaction, suggesting "a unidirectional (but not reciprocal) simultaneous relationship" (p. 902). Thus, many aspects of the relationship between SWB and health clearly deserve more attention. In the present study, we conceptualize SWB as an outcome variable and examine the change in the components of subjective well-being (SWB) over time in patients with osteoarthritis who have undergone total hip or knee replacement surgery (arthroplasty). We also examine whether pre-operative ratings of SRH status (both general and osteoarthritisspecific), as well as change in health status, can serve as predictors of postoperative levels of SWB.

\subsection{Components of SWB}

It has been suggested that SWB has three main components: life satisfaction (LS), positive affect (PA), and negative affect (NA) (Diener 1984; Tay and Diener 2011). However, research has shown that these three components of SWB are relatively independent, and that they may even have different causes (Diener 2013). There is also strong evidence that the strength of the relationship between LS and the affective components of SWB depends 
on many different factors, such as cultural values (Kuppens et al. 2008; Suh et al. 1998), age, and personality traits (Kööts-Ausmees et al. 2013). For this reason, we examine LS, PA, and NA separately in the following analyses, so as not to loose any valuable information about the three indicators of SWB by merging them (Diener 2000).

\subsection{Stability and Change of SWB Over Time in Response to Arthroplasty}

A meta-analysis by Luhmann et al. (2012) showed that major life events can have very different effects on SWB, and these can be both short- and long-term in nature. Interestingly, their findings also showed that the effects of most life events were stronger and more consistent across samples on LS than on the affective components of SWB.

Having surgery of any kind, especially when accompanied by major injury or longterm illness, is one of the life events which can have a significant effect on SWB. In this paper, we focus on osteoarthritis patients who have undergone a total knee or hip replacement (arthroplasty), a surgical procedure whereby the diseased knee or hip joint is replaced with artificial material (called a prosthesis). Total knee or hip replacement is a major event in a person's life which can evoke thoughts about the nature of life and death as well as feelings of both hope and fear (Gustafsson et al. 2010), and it is usually a last choice for people suffering from osteoarthritis when other treatments, such as medication, physical therapy, and lifestyle changes have not relieved pain enough or when chronic pain, stiffness, and other limitations caused by osteoarthritis have made coping with life very difficult (Singh 2011). Although the surgery is not without risks, people who have an arthroplasty usually have major improvement in their quality of life, sleep, and physical function, as well as degree of joint pain, especially during the first 3-6 months after surgery (Ethgen et al. 2004), but also in the longer term, at follow-up of 3 or more years (Shan et al. 2015).

Although numerous studies have examined the health-related quality of life in patients with a total hip or knee arthroplasty (see Ethgen et al. 2004; Shan et al. 2015 for systematic reviews), there are surprisingly few studies that have specifically examined SWB in osteoarthritis patients who have undergone an arthroplasty. Aarons et al. (1996) found, in a sample of 70 patients, that there was a significant improvement in NA seven days after arthroplasty with no later improvement, whereas PA and LS saw no improvement at all after the surgery, remaining at the same level even at 50 days postoperation. In another study involving 62 Dutch osteoarthritis patients with total hip replacements (Borstlap et al. 1994), there was some evidence of reduced anxiety and depression and of increased cheerfulness three to twelve months after surgery. Significant improvement in scores of LS (Salmon et al. 2001) as well as of anxiety and depression (Perruccio et al. 2011; Salmon et al. 2001) have been observed in different samples of osteoarthritis patients who were followed up three to four times after arthroplasty for a period of up to six months. In sum, although osteoarthritis patients see significant health improvements after arthroplasty compared to their preoperative status, the evidence is weak and inconclusive when it comes to changes in the different components of SWB after surgery.

\subsection{Research Aims}

The current paper has two interrelated aims. First, we examine the changes in SWB in patients with hip or knee osteoarthritis who have undergone an arthroplasty. While there is 
overwhelming evidence of osteoarthritis patients having improved physical health outcomes after an arthroplasty, compared to their preoperative status, does improved health lead to increases in SWB as well?

Secondly, we are interested in studying whether pre-operative ratings of SRH status, as well as change in health status, can serve as predictors for postoperative level of SWB. To this end, we measure general SRH, as well as osteoarthritis-specific health indicators, physical ability, comorbidity of other diseases, and medication use.

Several studies have suggested that personality is the strongest predictor or cause of SWB (DeNeve and Cooper 1998; Steel et al. 2008) and that SWB is linked to personality by common genes (Weiss et al. 2008). A recent large-scale meta-analysis of independent twin cohorts showed that the weighted average heritability estimate of SWB was about $35 \%$ (Bartels 2015). Personality traits may also influence the ratings of people's general SRH status through a shaping of their subjective interpretations of their objective health status (Löckenhoff et al. 2008). Therefore, we also control for the three personality traits-Neuroticism, Extraversion, and Conscientiousness-which appear to be the strongest predictors of SWB (DeNeve and Cooper 1998; Dobewall et al. 2013; Hayes and Joseph 2003; Lucas and Diener 2008; Steel et al. 2008; Weiss et al. 2008; Vitters $\varnothing 2001$ ) when examining the associations between health indicators and SWB.

Our study design has notable strengths and goes beyond earlier research in several important ways. First, this is one of the few studies which has examined changes in all three components of SWB-NA, PA, and LS—after a major life event (i.e., arthroplasty). Earlier research has shown that the three components of SWB are not uniformly related to one another (Kuppens et al. 2008; Kööts-Ausmees et al. 2013) and that even the same life events can affect the components of SWB very differently (Luhmann et al. 2012).

Second, when examining health status, we not only use people's ratings of their general SRH but also numerous more specific indicators of physical health such as osteoarthritisrelated health indicators, physical ability, comorbidity of other diseases, and medication use. Although people's rating of their general SRH is a relatively good reflection of their objectively measured health status (DeSalvo et al. 2006; Jylhä 2009; Mackenbach et al. 2002), it also has a substantial evaluative component (Kööts-Ausmees et al. 2016), so our study improves upon previous research by including more specific health-related questions in addition to people's ratings of their general SRH.

Third, when studying the associations between SWB and health indicators in a group of osteoarthritis patients, we also control for the three personality traits-Neuroticism, Extraversion, and Conscientiousness-which are strongly linked not only to SWB (DeNeve and Cooper 1998; Dobewall et al. 2013; Steel et al. 2008) but may also influence people's ratings of their subjective health (Kööts-Ausmees et al. 2016; Löckenhoff et al. 2008).

Last but not least, our longitudinal study design allows us to shed some light on the causal role of SRH status in SWB that is not yet fully understood. We examine whether people's preoperative ratings of SRH status can predict postoperative levels of the different components of SWB and, vice versa, in order to contribute to the discussion about the complex relationships between SWB and SRH status. Among other things, the answers to these questions will help to develop more effective psychological intervention programs for patients with osteoarthritis who plan to undergo or have already undergone arthroplasty. 


\section{Method}

\subsection{Participants}

Participants for the current study were recruited from the Orthopaedic Unit of the Pärnu Hospital Surgery Clinic from patients who had been admitted for total hip or knee replacement surgery (arthroplasty) during the period January to March 2008. Pärnu is the fourth largest city of Estonia, with a population slightly over 40,000. The criteria for inclusion in the current study were the following: (a) the participant had been diagnosed with a primary or secondary hip or knee arthrosis; (b) the hip or knee replacement surgery was going to take place at the Orthopaedic Unit of the Pärnu Hospital Surgery Clinic; (c) the participant was able to read and understand Estonian as well as fill in the questionnaire; (d) the participant gave informed consent to participate in the study. All data were collected by the second author of this article.

A total of 50 patients with a mean age of 64.9 years $(S D=9.2$; ranging from 43 to 82 years) participated in the study. Fifty-eight per cent of the participants $(n=29)$ were females. More than half of the participants $(n=27)$ had either secondary or secondary vocational education, $28 \%$ of the participants had elementary education, and $18 \%$ higher education.

Thirty-six participants (72\%) were scheduled to have a knee, and 14 (28\%) participants a hip, arthroplasty. There were no statistically significant differences in any variable of interest before surgery between participants who were having a knee or a hip arthroplasty. Therefore, the participants will be treated as a single group of osteoarthritis patients, regardless of their exact diagnosis. All participants first completed the questionnaire at the clinic 1 day before their operation (T1). On average 4.5 months after the operation ( $\mathrm{Me}$ dian $=136$ days, $S D=22.6$ days, varying from 94 to 175 days), 47 (94\%) of the initial 50 participants completed the questionnaire for the second time (T2). The three dropouts did not differ from the remaining participants in any of the variables of interest at T1.

\subsection{Measures}

\subsubsection{Subjective Well-Being (SWB)}

Life satisfaction was assessed with the Estonian version of the Satisfaction with Life Scale (SWLS; Diener et al. 1985; Pavot and Diener 1993). The scale consists of five items, for example, "So far I have gotten the important things I want in life" and "If I could live my life over, I would change almost nothing". Items were rated on a 5-point scale from 1 (strongly disagree) to 5 (strongly agree). The average score across the five items forms a score of LS. Cronbach alphas of the SWLS were .73 (T1) and .83 (T2). The SWLS scores at T1 and T2 were correlated at $r=.50(p<.0001)$.

Positive and negative affect. Participants' experience of positive and negative affect was measured by the Estonian version (Allik and Realo 1997) of the Positive and Negative Affect Schedule (PANAS; Watson et al. 1988). The PANAS consists of 20 mood terms, half of which measure positive affect (PA) and the other half negative affect (NA). Participants were instructed to indicate the extent to which they had felt each of the emotions over the previous two weeks. Items were scored on a 5-point Likert-like scale ranging from 1 (very slightly or not at all) to 5 (extremely). The Cronbach alphas of the PA scale were .81 (T1) and .89 (T2), and of the NA scale .83 (T1) and .91 (T2). The correlations between 
PA scores at T1 and T2 and between NA scores at T1 and T2 were $r=.38(p<.01)$ and $.54(p<.0001)$, respectively.

There were no statistically significant gender or age differences in the scores of SWLS, $\mathrm{NA}$, or PA at either $\mathrm{T} 1$ or T2, and, therefore, gender and age are not considered covariates in the following analyses.

\subsubsection{Health Status}

General self-reported health status. Participants' general SRH status was measured with the following question: "How do you rate your health?" Answers were given on the following scale: 1-I am completely healthy; 2-I am generally healthy; 3-I have some health problems but I get by; 4-my health is not particularly good, I cannot do everything I want to do; 5-generally speaking, my health is bad and requires constant care; 6-my health is very bad. In the subsequent analyses, scores are reversed so that higher scores indicate better health. The correlation between the ratings of general SRH status at T1 and T2 was not statistically significant, $r=.24, p=.110$.

Osteoarthritis-specific instrument of health. In order to assess pain, stiffness, and physical function in our participants with hip or knee osteoarthritis, we used the visual analogue version (VAS) of the Western Ontario and McMaster Universities Osteoarthritis

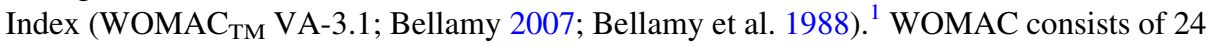
items that are divided into three subscales: pain (5 items), stiffness ( 2 items), and physical function (17 items). The items were answered using 100-mm visual analogue scales and, accordingly, the initial scores of the three subscales ranged from 0 to 500 (pain), 0 to 200 (stiffness), and from 0 to 1700 (physical functioning), with higher scores indicating more pain, more stiffness, and more difficulty in the performance of different everyday activities, respectively. All WOMAC data presented in this report have been normalized using average scores on 0 to 10 scales, where the best score possible is 0 and the worst is 10 (Bellamy et al. 2011). Cronbach alphas of the pain, stiffness, and physical function subscales were $.69, .58$, and .87 at $\mathrm{T} 1$ and $.89, .89$, and .96 at T2, respectively. The WOMAC scales were significantly correlated with one another $(p<.0001)$ both at T1 (mean $r=.57$ ) and $\mathrm{T} 2$ (mean $r=.72$ ), and therefore, total WOMAC scores at T1 and T2 were determined by summing the scores of the three subscales.

Other aspects of health. Participants' health was further evaluated in the following three ways:

(1) First, participants were asked if they used any aid for walking (e.g., a walking stick, crutches, a walking frame, or a wheelchair). Among the 47 participants who completed the questionnaire both at T1 and T2, $34 \%(16)$ at T1 and $38 \%$ (18) at T2 used some sort of walking aid. The difference between the two measurement occasions was not statistically significant, $p=.664$.

(2) Second, participants were asked if they had any other chronic health problems besides osteoarthritis. Thirty-six (72\%) participants at T1 and 29 (63\%) participants at T2 answered that they had other chronic health problem(s) in addition to osteoarthritis (the difference between T1 and T2 was not significant,

\footnotetext{
1 Permission to use the Estonian version of the WOMAC $_{\mathrm{TM}}$ VA-3.1 was obtained from the author of the scale, Prof. Nicholas Bellamy (Centre of National Research on Disability and Rehabilitation Medicine, Department of Medicine, The University of Queensland, Level 3, Mayne Medical School, Herston Road, Brisbane Queensland 4006, Australia, E-mail: n.bellamy@uq.edu.au). The respective academic user agreement was signed on the 17th of October 2007.
} 
$p=.334)$. The most common comorbid health condition both at $\mathrm{T} 1$ and $\mathrm{T} 2$ was hypertension, which was mentioned by $34 \%$ and $38 \%$ of participants, respectively.

(3) Finally, participants were asked how frequently they took painkillers. The question was answered along the following scale: 1—every day; 2-a few times a week; 3 - a few times a month; 4-less frequently or not at all. For the subsequent analyses, the scores were reversed so that higher scores indicate more frequent intake of painkillers.

\subsubsection{Personality Traits}

Finally, participants' personality traits were measured at T1 using the self-report version of the National Character Survey (NCS). The NCS (Terracciano et al. 2005) consists of 30 bipolar items intended to parallel the facets of the NEOPI-R (Costa and McCrae 1992) and respondents are asked to rate their personality using these items. The Estonian version of the NCS has been successfully used in an earlier study by Realo et al. (2009). NCS scores for the three traits were calculated as the sum of the six relevant facets/items.

\section{Results}

\subsection{Changes in Health Status Following Arthroplasty}

Means, standard deviations, and test-retest correlations of WOMAC scores and ratings of general SRH before and after arthroplasty are displayed in Table 1. The pre-operative

Table 1 Mean scores of SWLS, PANAS, and WOMAC scales and subjective health ratings at T1 (1 day before operation) and T2 (about 4.5 months after operation)

\begin{tabular}{|c|c|c|c|c|c|c|c|c|}
\hline & \multicolumn{2}{|c|}{$\mathrm{T} 1(N=50)$} & \multicolumn{2}{|c|}{$\mathrm{T} 2(N=47)$} & \multirow[t]{2}{*}{$F$} & \multirow[t]{2}{*}{$d f$} & \multirow[t]{2}{*}{$p$} & \multirow[t]{2}{*}{$r$} \\
\hline & $M$ & $S D$ & $M$ & $S D$ & & & & \\
\hline SWLS & 3.6 & 0.8 & 3.4 & 0.9 & 2.2 & 46 & .147 & $.50 * * *$ \\
\hline \multicolumn{9}{|l|}{ PANAS } \\
\hline PA & 25.0 & 5.5 & 27.2 & 6.4 & 4.8 & 44 & .035 & $.38 * *$ \\
\hline NA & 18.7 & 6.3 & 18.4 & 6.8 & 0.2 & 44 & .656 & $.54 * * *$ \\
\hline General SRH & 3.5 & 0.9 & 3.5 & 0.8 & 0.0 & 46 & .999 & .24 \\
\hline \multicolumn{9}{|l|}{ WOMAC } \\
\hline Pain & 4.2 & 1.8 & 1.3 & 1.7 & 95.9 & 46 & .000 & $.33 *$ \\
\hline Stiffness & 5.7 & 2.5 & 2.2 & 2.4 & 58.7 & 46 & .000 & .19 \\
\hline Physical functioning & 4.9 & 1.5 & 2.1 & 2.0 & 79.3 & 46 & .000 & .26 \\
\hline The WOMAC total score & 14.7 & 5.1 & 5.6 & 5.5 & 101.2 & 46 & .000 & .27 \\
\hline
\end{tabular}

$r=$ test-retest correlation between $\mathrm{T} 1$ and $\mathrm{T} 2$ measurements

SWLS The Satisfaction with Life Scale, PANAS The Positive and Negative Affect Schedule, PA Positive Affect, NA Negative Affect, General SRH General Self-Reported Health Status, WOMAC Western Ontario and McMaster Universities Osteoarthritis Index (WOMAC TM $_{\text {VA-3.1) }}$

$* * * p<.001 ; * * p<.01 ; * p<.05$ 
scores for pain, stiffness and physical function as assessed by the WOMAC in the current sample were all significantly higher (at $p<.0001$ ) than age-specific population-based normative values based on a sample of approximately 7300 Australians (Bellamy et al. 2011). ${ }^{2}$ As can be seen in Table 1 , however, participants experienced significantly less pain, stiffness, and difficulty with the performance of different daily activities at about 4.5 months after their arthroplasty (T2), compared to before the operation (T1) when using repeated measures analysis of variance (ANOVA). ${ }^{3}$ At T2, the WOMAC scores in the current sample did not significantly differ from the respective values for their age-matched peers in the general Australian population (Bellamy et al. 2011).

The improvement in participants' health from T1 to T2 could also be seen in the reduced frequency of taking painkillers. Before arthroplasty (T1), $36 \%$ (17) of the 47 participants took painkillers every day, $21 \%$ (10) a few times a week, $4 \%$ (2) a few times a month, and $38 \%$ (18) less frequently or not at all. At T2, only $4 \%$ (2) of participants took painkillers every day, $17 \%$ (8) a few times a week, $28 \%$ (13) a few times a month, and $50 \%$ (23) less frequently or not at all. One participant did not answer this question at T2. The difference between the frequency distributions at T1 and T2 was statistically significant, $C h i$ square $=19.9, d f=9, p=.02$. As noted in the Methods section, there were no statistically significant changes in participants' health status in terms of using a walking aid or having other chronic diseases from T1 to T2.

Participants' perception of their general SRH, however, was not influenced by having undergone the knee or hip arthroplasty ( $p=.999$; see Table 1$)$, despite the fact that significant improvements in their physical functioning could be demonstrated by the decreased WOMAC scores (i.e., less pain and stiffness, as well as less difficulty in the performance of different activities) and by the reduced intake of painkillers. Only $32 \%$ of the participants said that their health was better after the arthroplasty (T2) than before the surgery (T1). For $36 \%$ of the participants $(n=17)$, there was no change in their general SRH status before and after the arthroplasty, whereas $32 \%$ of participants argued that their health was in fact worse after the arthroplasty (T2) than before (T1).

\subsection{Changes in Subjective Well-Being Following Arthroplasty}

The three components of SWB (i.e., LS, PA, and NA) were not significantly correlated with each other at T1 (see Table 2). At T2, the only correlation that reached a significance level of $p<.05$ was between LS and PA, $r=.36(p=.016)$. The fact that the intercorrelations between the components of SWB were mostly not statistically significant further supported our earlier decision to use the three components of SWB separately in the subsequent analyses.

Similarly to general SRH, there were no significant changes in participants' rating of their LS or negative emotions, following the arthroplasty, as shown by the results of the repeated measures of ANOVA. However, the SWLS score in the current sample before arthroplasty $(M=3.6, S D=.8)$, but not after $(M=3.4, S D=.9)$, was significantly higher $(p<.001)$ than the respective age- and gender-specific score of the SWLS

\footnotetext{
2 The mean WOMAC subscale scores for pain, stiffness, and physical function in Bellamy et al.'s study (2011) for the age group 65-69 years were 1.68 (2.19), 2.32 (2.50), and 1.87 (2.29), respectively.

3 The change in the total WOMAC score in the current sample is similar to that which was reported by Tali and Maaroos (2011) for a sample of 26 Estonian female patients who completed the WOMAC inventory 1 day before and 3 months after arthroplasty.
} 


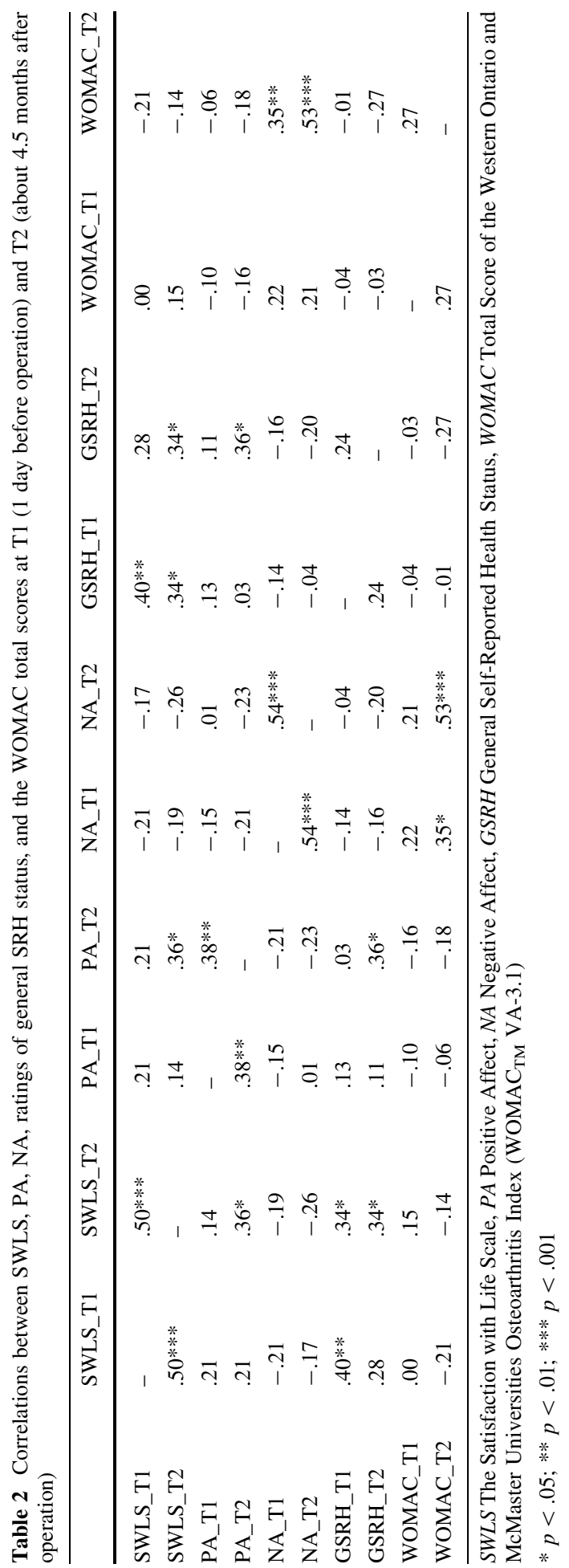


$(M=3.2, S D=.8)$ based on an age and gender-matched selection of the Estonian general population $(N=600$; mean age $=62.6$ years, $S D=11.6 ; 61 \%$ women $){ }^{4}$

The only change in SWB scores over the period of 4.5 months was in the level of PA: participants' level of PA was significantly higher at T2 $(M=27.2, S D=6.4)$ than at T1 $(M=25.0, S D=6.4), t(44)=2.2, p=.035$. The PA score in the sample of osteoarthritis patients after the arthroplasty, but not before, was significantly higher $(p<.05)$ than in an age- and gender-comparable sample of 55 individuals (mean age 68.2 years; $S D=5.5$, $76 \%$ women; mean PA score $=24.5, S D=6.0$ ) who were recruited for an experience sampling study (Kööts et al. 2011, 2012) from two day centers in Tartu (Estonia) that provide activities and lunches for older people. The scores of NA at both T1 $(M=18.7$, $S D=6.3)$ and $\mathrm{T} 2(M=18.4, S D=6.8)$ were significantly higher, at a significance level of $p<.05$, than in the above-mentioned control sample (mean NA score $=15.95$; $S D=4.69)$.

\subsection{Predicting SWB After Arthroplasty from Pre-operative Health Ratings}

Our second aim is to determine whether pre-operative health ratings serve as predictors for the postoperative level of SWB, and whether these relationships persist when three Big Five personality traits are added to the model. All correlations between SWB components and health ratings at $\mathrm{T} 1$ and $\mathrm{T} 2$ are shown in Table 2. In order to control for the baseline effects, a change score was calculated separately for LS, PA, and NA by subtracting the baseline (T1) score from the follow up (T2) score, with higher positive scores indicating a greater increase in LS, PA, and NA scores from T1 to T2, respectively.

We conducted a series of hierarchical linear regression analyses, using IBM Statistical Package for Social Sciences (IBM SPSS version 23). Altogether, four blocks of variables were added as predictors of LS at T2 to the regression model: (1) a change score of LS from T1 to T2; (2) general SRH at T1; (3) the WOMAC total score and other health ratings (i.e., intake of painkillers, use of walking aids, and comorbid health problems) at $\mathrm{T} 1$; and (4) three FFM personality traits (i.e., Neuroticism, Extraversion, and Conscientiousness) at T1. All variables within a block were, as a rule, entered simultaneously. Similar models were run for NA and PA at T2.

All nine variables explained about $46.3 \%$ of the variance in LS at T2. Higher levels of LS after arthroplasty were significantly associated with increased levels of LS from T1 to $\mathrm{T} 2(\beta=.56, p<.0001)$ and better general SRH at T1 $(\beta=.34, p=.004)$. In case of PA, only a higher increase in PA from $\mathrm{T} 1$ to $\mathrm{T} 2(\beta=.53, p<.0001)$ made a significant contribution to predicting the experience of PA after arthroplasty, with all nine variables explaining $42.0 \%$ of the variance. Finally, the experience of NA after arthroplasty was significantly predicted by a higher increase in NA scores from T1 to T2 ( $\beta=.63$, $p<.0001)$ but also by higher WOMAC total $(\beta=.35, p=.012)$ and Neuroticism $(\beta=.31, p=.041)$ scores before arthroplasty. Altogether, the nine variables explained $35.5 \%$ of the variance in NA at T2.

\footnotetext{
4 The Estonian population-based SWLS data were collected within the framework of the 4th wave of the biennial multi-country survey, the European Social Survey (the ESS4, http://www.europeansocialsurvey. org/), in 2008. The ESS is an hour-long face-to-face interview and the survey involves strict random probability sampling and rigorous translation protocols.
} 


\subsection{Predicting SWB After Arthroplasty from Changes in Self-Rated Health Status Following Surgery}

We were also interested in examining whether the components of SWB at T2 (i.e., 4.5 months after arthroplasty) can be predicted from changes in health status following arthroplasty. To this end, we first calculated the difference in the general SRH status from $\mathrm{T} 1$ to $\mathrm{T} 2$, with positive scores indicating improved general SRH and negative scores indicating a worsening in general SRH. We also calculated (a) the difference between the WOMAC general scores before and after arthroplasty, with higher positive scores indicating a greater improvement in pain, stiffness, and physical functioning after arthroplasty, and (b) change in the use of painkillers, with higher scores indicating a greater reduction in the use of painkillers at T2 compared to T1. Since there were no statistically significant changes in participants' health status in terms of using a walking aid or having other chronic diseases from $\mathrm{T} 1$ to $\mathrm{T} 2$, these two variables were not included in the analyses.

Next, we predicted LS, NA, and PA scores at T2 from the health change scores using hierarchical linear regression analysis while also controlling for the baseline effects of the three SWB components and personality traits. More specifically, four blocks of variables were added as predictors of LS at T2 to the regression model: (1) a change score of LS from T1 to T2; (2) a change score of general SRH from T1 to T2; (3) a difference between the WOMAC general scores before and after arthroplasty and a change score of the intake of painkillers from $\mathrm{T} 1$ and $\mathrm{T} 2$; and (4) three FFM personality traits (i.e., Neuroticism, Extraversion, and Conscientiousness) at T1. All variables within a block were entered simultaneously. Similar models were run for NA and $\mathrm{PA}$ at $\mathrm{T} 2$.

Only the change in the levels of LS and NA from T1 to T2 served as important predictors for LS and NA scores at T2, respectively. For the experience of PA at T2, however, also the change in the use of painkillers $(\beta=.30, p=.023)$ made a significant contribution to the prediction of PA after surgery even when personality traits and the change in PA levels were controlled for.

\subsection{Causality of the Relationships Between SWLS and General SRH}

As we showed above, general SRH at T1, that is, before arthroplasty, was a significant predictor of people's ratings of LS after arthroplasty, even when other health-related indicators, basic personality traits, and the change score from T1 to T2 were controlled for. In order to shed some light on the causality of the relationship between LS and general SRH, we also ran a hierarchical multiple regression analysis where we predicted general SRH after arthroplasty from (1) a change score of general SRH status from T1 to T2; (2) LS at T1; (3) the WOMAC total score and other health ratings (i.e., intake of painkillers, use of walking aids, and comorbid health problems) at T1; and (4) three FFM personality traits (i.e., Neuroticism, Extraversion, and Conscientiousness) at T1. All nine variables explained $44.6 \%$ of the variance in general SRH at T2. Better general SRH after arthroplasty was significantly associated with a greater improvement in general SRH status from T1 to T2 $(\beta=.47, p<.001)$ as well as with higher levels of LS at T1 $(\beta=.31, p=.013)$, the latter suggesting a reciprocal relationship between SWLS and general SRH. 


\section{Discussion}

Earlier research has shown that major life events can have various both short- and longterm effects on SWB, and that the effects of most life events appear to be stronger on LS than on the affective components of SWB (Luhmann et al. 2012). In the current study, we examined the change in SWB levels in a group of osteoarthritis patients approximately 4.5 months after arthroplasty. Our results showed that, while there were significant improvements in participants' health and physical functioning after arthroplasty compared to their preoperative status, there were no changes in ratings of general SRH, LS, or NA. The only change in SWB scores was in the level of PA, which was significantly higher after surgery compared with the pre-operative measurement. This confirms earlier findings by Diener et al. (2006), who showed that the various components of SWB exhibit differential stability, and that long-term levels of NA appear to be more stable than long-term levels of PA. However, our findings are not completely compatible with Aarons et al. (1996), who showed that there was a significant early improvement in NA at 7 days after arthroplasty with no later improvement, whereas PA and LS did not change after arthroplasty or at follow-up, about 2 months after surgery. Due to our study design, unfortunately, we cannot say anything about the change in SWB right after arthroplasty. It is known that people adapt to many life events and that this adaptation often happens within a relatively short period of time (Diener et al. 2006), but the process of adaptation is not automatic and there are still several unanswered questions regarding if, how, and when adaptation to a life event occurs. Thus, we do not know whether, or to what extent, the level of SWB of our participants changed immediately following arthroplasty, or whether 4.5 months is long enough for adaptation to occur.

However, it should also be noted that the participants in our study reported significantly higher levels of LS than people in the general population before, but not after, arthroplasty. Thus, it may be that the level of LS among our participants was already elevated before arthroplasty in anticipation of surgery and the consequent expected improvement in healthrelated quality of life, and that the non-significant decrease in the level of LS after arthroplasty is in fact an effect of adaptation. The level of PA among our respondents, however, was higher than in the control group only after arthroplasty, suggesting that the significant change in the level of PA from T1 to T2 may be due to the perceived positive changes in health status - most notably to the reduced consumption of painkillers-following arthroplasty. We also found that our participants with osteoarthritis reported significantly more negative affect than controls did, both before and after surgery. This in line with earlier research that shows that negative affect often develops as a consequence of chronic pain (Huyser and Parker 1999), something from which people with osteoarthritis greatly suffer (Schaible 2012).

Our findings also showed that the three components of SWB were relatively weakly associated with each other, with only LS and PA scores after arthroplasty being significantly correlated with each other at a significance level of $p<.05(r=.36)$. The independence of the SWB facets was further supported by the fact that they were differently related to the various health indicators. When we predicted our participants' SWB after arthroplasty from their general SRH status, three basic personality traits, the WOMAC total score, and other health ratings (i.e., intake of painkillers, use of walking aids, and comorbid health problems) at T1 while also controlling for the base-line level of SWB, better general SRH status was the only statistically significant predictor of LS after arthroplasty, whereas NA after arthroplasty was significantly predicted by the higher 
WOMAC score (indicating more pain, more stiffness, and more difficulty in the performance of different everyday activities) and by higher levels of Neuroticism before arthroplasty. Finally, only the change in the use of painkillers at T2 compared to T1 made a significant contribution to the prediction of PA after surgery, meaning that those participants who had a greater reduction in the use of painkillers after arthroplasty also had higher post-surgery levels of PA.

Interestingly, general SRH status, which has repeatedly been shown to relate to SWB (see Friedman and Kern 2014, for a review), was only associated with the cognitive component of SWB-LS-in our study. Thus, it appears that the link between general SRH and SWB (see also Kööts-Ausmees et al. 2016) is, first and foremost, due to the evaluative component inherent in both LS (Pavot and Diener 1993) and general SRH (Jylhä 2009) assessments. The more specific health indicators, such as the experience of pain, stiffness, or more difficulties in the performance of different everyday activities, were more strongly associated with the affective components of SWB. In sum, our findings clearly imply that further studies should focus on the independent ability of SWB components to "predict health outcomes beyond a general SWB factor score" (Diener and Chan 2011, p. 27), as well as vice versa, which is what we did in the current study.

Finally, the longitudinal nature of the data allowed us to shed some light on causality in the relationship between LS and general SRH, which is, to date, far from being fully understood (e.g., Friedman and Kern 2014). In the present study, we conceptualized SWB as an outcome variable and found that general SRH status at T1, that is, before arthroplasty, was a significant predictor of people's ratings of LS after arthroplasty, even when LS at baseline and basic personality traits were controlled for. In order to examine causality in the relationship, we also predicted general SRH after arthroplasty from the LS ratings at $\mathrm{T} 1$ and found that better general SRH after arthroplasty was predicted not only by a greater improvement in general SRH status from T1 to T2 but also by higher levels of LS before arthroplasty. Thus, although there is a growing body of evidence indicating that SWB causally contributes to health, with initial levels of SWB predicting important health outcomes in later life (Chida and Steptoe 2008; Diener and Chan 2011), our findings suggest that the relationship between the ratings of general SRH status and LS is likely to be reciprocal, that is the ratings of general SRH affecting LS and conversely, LS affects the ratings of general SRH.

\subsection{Limitations and Practical Implications}

As in most research, our study had some notable limitations. First, the size of our sample was fairly small, which clearly limits the conclusions that can be drawn. Second, as mentioned, we only measured participants' level of SWB and health status twice: 1 day before arthroplasty and about 4.5 months after arthroplasty. For this reason, we cannot say for certain if and when adaptation to a life event such as this occurs. Yet, there are several important strengths of our study that outweigh these limitations, including the prospective study design and the use of different indicators to measure SWB and physical health.

Our findings clearly suggest that when examining the associations between health and SWB, the components of SWB should be assessed as distinct constructs-it is the cognitive-evaluative component of SWB (i.e., LS) that is mostly responsible for the association between general SRH and SWB while affective components (i.e., NA and PA) are primarily related to more specific health indicators.

Our results also showed that despite substantial improvements in participants' physical functioning and health status about 4.5 months after arthroplasty compared to their 
preoperative status - they had significantly less pain and stiffness, less difficulty in the performance of different activities and took fewer painkillers-the participants only reported higher levels of PA but not better general SRH, higher LS, or lower NA after arthroplasty. These findings can assist physicians in their efforts to provide more realistic expectations for their patients undergoing surgery In terms of the physical and psychological outcome.

Acknowledgments We thank Jüri Allik and Delaney Michael Skerrett for their helpful comments on earlier drafts of this article.

Funding Preparation of this manuscript was supported by the University of Tartu (SP1GVARENG) and by institutional research funding (IUT2-13) from the Estonian Ministry of Education and Science. Anu Realo was a Visiting Professor in the Health, Medical, and Neuropsychology Unit of the Faculty of Social and Behavioral Sciences at Leiden University during the writing of this article. She was also supported by a grant from the Netherlands Institute for Advanced Study (NIAS) during the preparation of the first draft of this manuscript.

\section{Compliance with Ethical Standards}

Ethical Approval This research was approved by the Ethics Review Committee (ERC) on Human Research of the University of Tartu (approval 163/T-11, 24 September 2007). All participants gave informed written consent to participate in the study.

Conflict of interest All authors declare that they have no conflict of interest with respect to the research, authorship, and/or publication of this article.

Open Access This article is distributed under the terms of the Creative Commons Attribution 4.0 International License (http://creativecommons.org/licenses/by/4.0/), which permits unrestricted use, distribution, and reproduction in any medium, provided you give appropriate credit to the original author(s) and the source, provide a link to the Creative Commons license, and indicate if changes were made.

\section{References}

Aarons, H., Hall, G., Hughes, S., \& Salmon, P. (1996). Short-term recovery from hip and knee arthroplasty. The Journal of Bone and Joint Surgery, 78, 555-558.

Allik, J., \& Realo, A. (1997). Emotional experience and its relation to the Five-Factor Model in Estonian. Journal of Personality, 65, 625-647.

Angner, E., Ray, M. N., Saag, K. G., \& Allison, J. J. (2009). Health and happiness among older adults: A community-based study. Journal of Health Psychology, 14, 503-512.

Bartels, M. (2015). Genetics of wellbeing and its components satisfaction with life, happiness, and quality of life: A review and meta-analysis of heritability studies. Behavioral Genetics, 45, 137-156.

Bellamy, N. (2007). WOMAC Osteoarthritis Index user guide. Version VIII. Brisbane.

Bellamy, N., Buchanan, W. W., Goldsmith, C. H., Campbell, J., \& Stitt, L. W. (1988). Validation study of WOMAC: A health status instrument for measuring clinically important patient relevant outcomes to antirheumatic drug therapy in patients with osteoarthritis of the hip or knee. Journal of Rheumatology, $15,1833-1840$.

Bellamy, N., Wilson, C., \& Hendrikz, J. (2011). Population-based normative values for the Western Ontario and McMaster (WOMAC) Osteoarthritis index: Part I. Osteoarthritis, 41, 139-148.

Borstlap, M., Zant, J. L., Van Soesbergen, M., \& Van der Korst, J. K. (1994). Effects of total hip replacement on quality of life in patients with osteoarthritis and in patients with rheumatoid arthritis. Clinical Rheumatology, 13, 45-50.

Brief, A. P., Butcher, A. H., George, J. M., \& Link, K. E. (1993). Integrating bottom-up and top-down theories of subjective well-being: The case of health. Journal of Personality and Social Psychology, 64, 646-653. 
Chida, Y., \& Steptoe, A. (2008). Positive psychological well-being and mortality: A quantitative review of prospective observational studies. Psychosomatic Medicine, 70, 741-756.

Costa, P. T, Jr., \& McCrae, R. R. (1992). Revised NEO Personality Inventory (NEO-PI-R) and NEO FiveFactor Inventory (NEO-FFI) professional manual. Odessa, FL: Psychological Assessment Resources.

DeNeve, K. M., \& Cooper, H. (1998). The happy personality: A meta-analysis of 137 personality traits and subjective well-being. Psychological Bulletin, 124, 197-229.

DeSalvo, K. B., Bloser, N., Reynolds, K., He, J., \& Muntner, P. (2006). Mortality prediction with a single general self-rated health question: A meta-analysis. Journal of General Internal Medicine, 21, 267-275.

Diener, E. (1984). Subjective well-being. Psychological Bulletin, 95, 542-575.

Diener, E. (2000). Subjective well-being: The science of happiness and a proposal for a national index. American Psychologist, 55, 34-43.

Diener, E. (2013). The remarkable changes in the science of subjective well-being. Perspectives on Psychological Science, 8, 663-666.

Diener, E., \& Chan, M. Y. (2011). Happy people live longer: Subjective well-being contributes to health and longevity. Applied Psychology: Health and Well-Being, 3, 1-43.

Diener, E., Emmons, R. A., Larsen, R. J., \& Griffin, S. (1985). The satisfaction with life scale. Journal of Personality Assessment, 49, 71-75.

Diener, E., Lucas, R. E., \& Scollon, C. N. (2006). Beyond the hedonic treadmill—Revising the adaptation theory of well-being. American Psychologist, 61, 305-314.

Diener, E., Oishi, S., \& Lucas, R. E. (2009). Subjective well-being: The science of happiness and life satisfaction. In C. R. Snyder \& D. J. Lopez (Eds.), The handbook of positive psychology (2nd ed., pp. 187-194). New York, NJ: Oxford University Press.

Dobewall, H., Realo, A., Allik, J., Esko, T., \& Metspalu, A. (2013). Self-other agreement in happiness and life-satisfaction: The role of personality traits. Social Indicators Research, 114, 479-492.

Ethgen, O., Bruyere, O., Richy, F., Dardennes, C., \& Reginster, J. Y. (2004). Health-related quality of life in total hip and total knee arthroplasty: A qualitative and systematic review of the literature. The Journal of Bone and Joint Surgery, 86-a, 963-974.

Friedman, H. S., \& Kern, M. L. (2014). Personality, well-being, and health. Annual Review of Psychology, $65,719-742$.

Gana, K., Bailly, N., Saada, Y., Joulain, M., Trouillet, R., Herve, C., \& Alaphilippe, D. (2013). Relationship between life satisfaction and physical health in older adults: A longitudinal test of cross-lagged and simultaneous effects. Health Psychology, 32, 896-904.

George, L. K., \& Landerman, L. R. (1984). Health and subjective well-being: A replicated secondary data analysis. International Journal of Aging and Human Development, 19, 133-156.

Gustafsson, B. A., Ekman, S. L., Ponzer, S., \& Heikkila, K. (2010). The hip and knee replacement operation: an extensive life event. Scandinavian Journal of Caring Sciences, 24, 663-670.

Hayes, N., \& Joseph, S. (2003). Big 5 correlates of three measures of subjective well-being. Personality and Individual Differences, 34, 723-727.

Huyser, B. A., \& Parker, J. C. (1999). Negative affect and pain in arthritis. Rheumatic Disease Clinics of North America, 25, 105-121.

Jylhä, M. (2009). What is self-rated health and why does it predict mortality? Towards a unified conceptual model. Social Science and Medicine, 69, 307-316.

Kööts, L., Realo, A., \& Allik, J. (2011). The influence of the weather on affective experience: An experience sampling study. Journal of Individual Differences, 32, 74-84.

Kööts, L., Realo, A., \& Allik, J. (2012). Relationship between linguistic antonyms in momentary and retrospective ratings of happiness and sadness. Journal of Individual Differences, 33, 43-53.

Kööts-Ausmees, L., Realo, A., \& Allik, J. (2013). The relationship between life satisfaction and emotional experience in 21 European countries. Journal of Cross-Cultural Psychology, 44, 223-244.

Kööts-Ausmees, L., Schmidt, M., Esko, T., Metspalu, A., Allik, J., \& Realo, A. (2016). The role of the five factor personality traits in self-reported general health. European Journal of Personality. doi:10.1002/ per.2058.

Kuppens, P., Realo, A., \& Diener, E. (2008). The role of positive and negative emotions in life satisfaction judgment across nations. Journal of Personality and Social Psychology, 95, 66-75.

Löckenhoff, C. E., Sutin, A. R., Ferrucci, L., \& Costa, P. T, Jr. (2008). Personality traits and subjective health in the later years: The association between NEO-PI-R and SF-36 in advanced age is influenced by health status. Journal of Research in Personality, 42, 1334-1346.

Lucas, R. E., \& Diener, E. (2008). Personality and subjective well-being. In O. John \& R. W. Robins (Eds.), Handbook of Personality: Theory and Research (pp. 795-814). New York: Guilford Press. 
Luhmann, M., Hofmann, W., Eid, M., \& Lucas, R. (2012). Subjective well-being and adaptation to life events: A meta-analysis on differences between cognitive and affective well-being. Journal of Personality and Social Psychology, 102, 592-615.

Luhmann, M., Lucas, R. E., Eid, M., \& Diener, E. (2013). The prospective effect of life satisfaction on life events. Social Psychological and Personality Science, 4, 39-45.

Lyubomirsky, S., King, L., \& Diener, E. (2005). The benefits of frequent positive affect: Does happiness lead to success? Psychological Bulletin, 131, 803-855.

Mackenbach, J. P., Simon, J. G., Looman, C. W., \& Joung, I. M. (2002). Self-assessed health and mortality: Could psychosocial factors explain the association? International Journal of Epidemiology, 31, 1162-1168.

Okun, M. A., \& George, L. K. (1984). Physician- and self-ratings of health, neuroticism and subjective wellbeing among men and women. Personality and Individual Differences, 5, 533-539.

Okun, M. A., Stock, W. A., Haring, M. J., \& Witter, R. A. (1984). Health and subjective well-being: A metaanalysis. International Journal of Aging and Human Development, 19, 111-132.

Pavot, W., \& Diener, E. (1993). Review of the satisfaction with life scale. Psychological Assessment, 5, 164-172.

Perruccio, A. V., Davis, A. M., Hogg-Johnson, S., \& Badley, E. M. (2011). Importance of self-rated health and mental well-being in predicting health outcomes following total joint replacement surgery for osteoarthritis. Arthritis Care \& Research, 63, 973-981.

Realo, A., Allik, J., Lönnqvist, J. E., Verkasalo, M., Kwiatkowska, A., Kööts, L., \& Renge, V. (2009). Mechanisms of the national character stereotype: How people in six neighbouring countries of Russia describe themselves and the typical Russian. European Journal of Personality, 23, 229-249.

Salmon, P., Hall, G. M., Peerbhoy, D., Shenkin, A., \& Parker, C. (2001). Recovery from hip and knee arthroplasty: Patients' perspective on pain, function, quality of life, and well-being up to 6 months postoperatively. Archives of Physical Medicine and Rehabilitation, 82, 360-366.

Schaible, H. G. (2012). Mechanisms of chronic pain in osteoarthritis. Current Rheumatology Reports, 14, 549-556.

Shan, L., Shan, B., Suzuki, A., Nouh, F., \& Saxena, A. (2015). Intermediate and long-term quality of life after total knee replacement: A systematic review and meta-analysis. The Journal of Bone and Joint Surgery, 97, 156-168.

Singh, J. A. (2011). Epidemiology of knee and hip arthroplasty: A systematic review. The Open Orthopaedics Journal, 5, 80-85.

Steel, P., Schmidt, J., \& Shultz, J. (2008). Refining the relationship between personality and subjective wellbeing. Psychological Bulletin, 134, 138-161.

Suh, E., Diener, E., Oishi, S., \& Triandis, H. C. (1998). The shifting basis of life satisfaction judgments across cultures: Emotions versus norms. Journal of Personality and Social Psychology, 74, 482-493.

Tali, M., \& Maaroos, J. (2011). Põlveliigese osteoartroosiga naispatsientide liikumisfunktsiooni ja elukvaliteedi taastumine endoproteesimise järel. Eesti Arst, 90, 174-180.

Tay, L., \& Diener, E. (2011). Needs and subjective well-being around the world. Journal of Personality and Social Psychology, 101, 354-365.

Terracciano, A., Abdel-Khalek, A. M., Adam, N., Adamovova, L., Ahn, C., Ahn, H. N., \& McCrae, R. R. (2005). National character does not reflect mean personality trait levels in 49 cultures. Science, 310, 96-100.

Vittersø, J. (2001). Personality traits and subjective well-being: Emotional stability, not extraversion, is probably the important predictor. Personality and Individual Differences, 31, 903-914.

Watson, D., Clark, L. A., \& Tellegen, A. (1988). Development and validation of brief measures of positive and negative affect: The PANAS scales. Journal of Personality and Social Psychology, 54, 1063-1070.

Watten, R. G., Vassend, O., Myhrer, T., \& Syversen, J.-L. (1997). Personality factors and somatic symptoms. European Journal of Personality, 11, 57-68.

Weiss, A., Bates, T. C., \& Luciano, M. (2008). Happiness is a personal(ity) thing: The genetics of personality and well-being in a representative sample. Psychological Science, 19, 205-210. 